\title{
Antagonistic interactions peak at intermediate genetic distance in clinical and laboratory strains of Pseudomonas aeruginosa
}

\author{
Sijmen E Schoustra ${ }^{1,2^{*}}$, Jonathan Dench ${ }^{1}$, Rola Dali ${ }^{1}$, Shawn D Aaron ${ }^{3}$ and Rees Kassen ${ }^{1}$
}

\begin{abstract}
Background: Bacteria excrete costly toxins to defend their ecological niche. The evolution of such antagonistic interactions between individuals is expected to depend on both the social environment and the strength of resource competition. Antagonism is expected to be weak among highly similar genotypes because most individuals are immune to antagonistic agents and among dissimilar genotypes because these are unlikely to be competing for the same resources and antagonism should not yield much benefit. The strength of antagonism is therefore expected to peak at intermediate genetic distance.

Results: We studied the ability of laboratory strains of Pseudomonas aeruginosa to prevent growth of 55 different clinical $P$. aeruginosa isolates derived from cystic fibrosis patients. Genetic distance was determined using genetic fingerprints. We found that the strength of antagonism was maximal among genotypes of intermediate genetic distance and we show that genetic distance and resource use are linked.
\end{abstract}

Conclusions: Our results suggest that the importance of social interactions like antagonism may be modulated by the strength of resource competition.

\section{Background}

The production by microorganisms of proteinaceous anticompetitor toxins such as bacteriocins is often cited as a good example of an antagonistic trait [1]. The evolution of antagonistic interactions is difficult to understand because they directly harm both actor and recipient. At the level of an individual gene, this apparent paradox can be readily resolved using the framework of inclusive fitness [2], which shows that antagonistic interactions can evolve provided they produce a net benefit to actors, even if the act of antagonism itself is costly.

Bacteriocin production has the hallmark of a classic antagonistic trait that can evolve through its effects on inclusive fitness. Bacteriocins are produced by nearly all bacteria and are considered the main agents in direct antagonistic interactions between and within bacterial species [3-6]. The production of bacteriocins is costly,

\footnotetext{
* Correspondence: Sijmen.Schoustra@wur.nl

'Biology Department, University of Ottawa, 30 Marie Curie, Ottawa, ON K1N 6N5, Canada

Full list of author information is available at the end of the article
}

both in terms of the energy diverted away from other functions such as growth and, in Gram-negatives at least, because bacteriocin-producing cells release their bacteriocins through lysis and so cause cell death [5]. Importantly, cells that are isogenic to the producing strain (typically a small fraction of cells within a population produce bacteriocins at any given time) are immune to the bacteriocin, usually via an immunity protein, and so gain a benefit from bacteriocin production from clone-mates. It has also been repeatedly noted that bacteriocins are highly specific in their action, being active primarily against genetically distinct members of the same species or species closely related to the producing strain $[3,7]$.

We suggest that the mechanism underlying the variation in the antagonistic effects of toxins like bacteriocins is caused by intraspecific resource competition. We expect that the ability of these toxins to remove competitors, and so free up resources, would evolve to be maximal when resource competition is strongest among genetically distinct individuals. The logic behind this is straightforward. Toxin production should not be
C Biomed Central

() 2012 Schoustra et al; licensee BioMed Central Ltd. This is an Open Access article distributed under the terms of the Creative Commons Attribution License (http://creativecommons.org/licenses/by/2.0), which permits unrestricted use, distribution, and reproduction in any medium, provided the original work is properly cited. 
favoured when competing with genetically identical clones because there is no fitness benefit to production. As genetic distance increases, however, so too does phenotypic and ecological divergence $[8,9]$, and by extension resource competition. Toxin production is therefore wasted when competing against genetically very divergent strains because there is little resource competition. In other words, toxin production becomes costly because its benefits are diluted by the fact that the producer and target strain do not compete with each other.

This interpretation leads to the prediction that the strength of antagonism should peak at intermediate genetic distance. To test this prediction we studied the interaction between two producer strains that produce a multitude of bacteriocins and a range of sensitive 'victim' strains of varying genetic distance to the producers. Specifically, we measured the ability of anticompetitor toxins produced by two laboratory strains of Pseudomonas aeruginosa, PA01 and PA14, to kill or inhibit 55 clinical strains of $P$. aeruginosa isolated from the lungs of cystic fibrosis (CF) patients. Natural communities of microbes associated with chronic infections such as colonization of the cystic fibrosis lung are often highly diverse [10-13]. We also measured the degree of ecological similarity among strains, using commercially available BIOLOG plates that contain 95 different carbon substrates, and show that ecological similarity can decrease with genetic distance. This result is consistent with the idea that toxin production is not favoured among genetically divergent strains because of a lack of resource competition.

\section{Pyocins and Pseudomonas aeruginosa}

$P$. aeruginosa produces a wide variety of toxins and among the most interesting, in part because they are known to be highly specific in their action, are bacteriocins called pyocins. They are costly to produce because they are released by cell lysis of a fraction of the producer population. Pyocins are proteinaceous compounds that are classified into three groups (R-, F-, and S-type), with multiple sub-types within each group that attach to different potential receptors in target strains $[5,14,15]$. PA01 is known to produce all three pyocins while PA14 produces only R- and F-type pyocins [4]. Genes coding for production of all pyocins are located on the chromosome and are clustered with genes coding for resistance to the same pyocins. Genomic studies have suggested the presence of more pyocins [16-19], both from the S- and Rtypes. In addition, a recently developed genome-mining tool for bacteriocins has revealed the general existence of yet to be characterized bacteriocins in several bacterial species [20]. Other toxins produced by $P$. aeruginosa include virulence factors such as exotoxin A, PCN and Y as well as membrane vesicles [21-23].

The clinical strains in our study come from a multicentre Canadian study of the epidemiology of chronic P. aeruginosa infections of CF patients [24], see Methods. Chronic infection with P. aeruginosa occurs in $60-70 \%$ of Canadian adults with CF [25]. After confirmation using standard techniques that the isolates were $P$. aeruginosa (Methods), genetic distance among all strains was estimated by comparing banding patterns of a full genome digest using pulsed field gel electrophoresis, PFGE [26-30]. We also confirmed that genetic distance correlates with the degree of overlap in resource use, measured by the ability of strains to metabolize 95 different carbon substrates found on commercially available Biolog plates.

\section{Results and discussion}

We measured the level of inhibition by anticompetitor toxins by spotting a dilution series of a cell free extract collected from $48 \mathrm{~h}$ old P. aeruginosa PA01 or PA14 culture onto a lawn of one of 55 different clinical isolates growing on a solid surface. The natural isolates differ in their genetic distance to the producing strain; genetic distance is quantified using full genome digests. The lowest concentration of cell free extract that gave rise to inhibition of the clinical isolate was used to calculate the inhibition score (Figure 1) $[14,15,31,32]$. Figure 2 depicts the level of inhibition by both PA01 and PA14 as a function of genetic distance of toxin producing strain to the clinical isolates.

Our results lend strong support to the idea that toxins are most effective when active against genotypes of intermediate genetic distance relative to the focal strain. The relationship between inhibition and genetic distance is unimodal, peaking at intermediate genetic distance for both toxin producers PA01 and PA14. This result is confirmed more formally by noting that a quadratic model with an internal maximum is a better descriptor of the data than a linear model (Table 1; in the linear regressions, the linear term is not significant), by the lower AIC (Aikake's Information Criterion) values for the quadratic models than the linear models (Table 1) and by an F-ratio test asking if adding the quadratic term provides a significantly better fit than the linear model (PA01, $\mathrm{F}_{1,48}=5.96$, $P=0.018$; PA14, $\left.F_{1,42}=17.56, P=0.00014\right)$. We also tested for the existence of an internal maximum in the data using a Mitchell-Olds and Shaw (MOS) test (as implemented in the R package vegan) following Mittelbach et al. (2001) [33]. This approach tests the null hypothesis that a quadratic function, fitted to the data, has no stationary point (either a maximum or minimum) within the range provided. Our results reject this null 


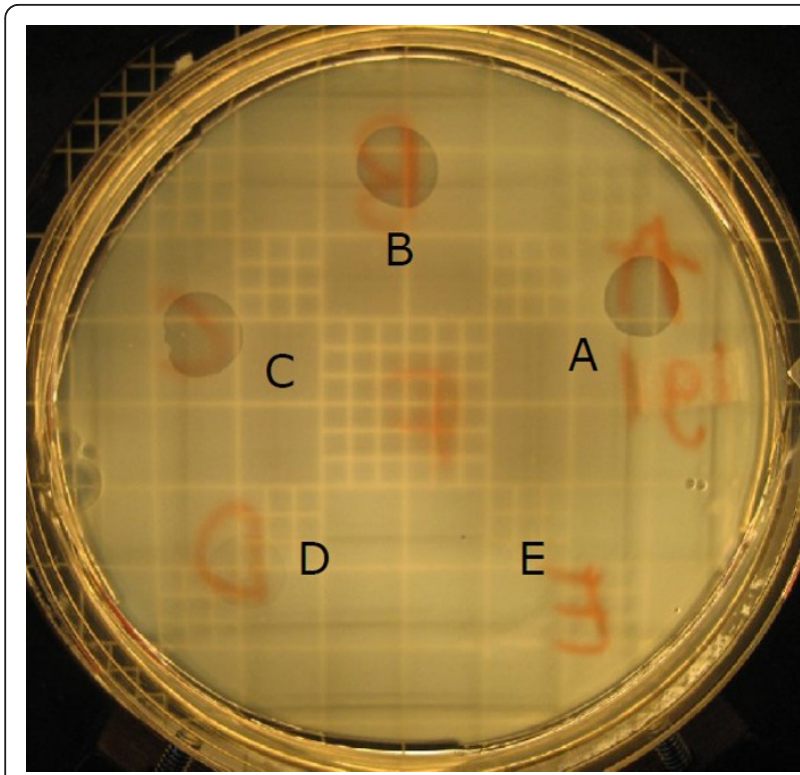

Figure 1 Inhibition assay. Lawn of a Pseudomonas aeruginosa natural isolate growing on the surface of an agar plate. Spots of pyocin containing cell free extract from a laboratory strain of $P$. aeruginosa PA01 were applied on the lawn at different dilutions. The formation of clear zones is indicative of killing of the clinical isolate. The highest dilution of cell free extract (thus containing the lowest concentration of toxin) that inhibits the clinical isolate is a measure of potency of the toxin. The inhibition score is the inverse of the highest dilution that inhibits growth of the clinical isolate. In this example, the spot marked $A$ is non-diluted cell free extract; spots $B$ to $F$ are serial 3-fold dilutions. The inverse of the dilution factor of dilution $\mathrm{D}$ would be the inhibition score.

hypothesis for both PA01 and PA14 at the $P<0.1$ level (PA01: $P=0.072$; PA14: $P=0.0006$ ), the same criterion used in Mittelbach et al. (2001) [33]. Since the sign of the quadratic coefficient for both producer strains was negative, the results of the MOS test indicate the presence of a

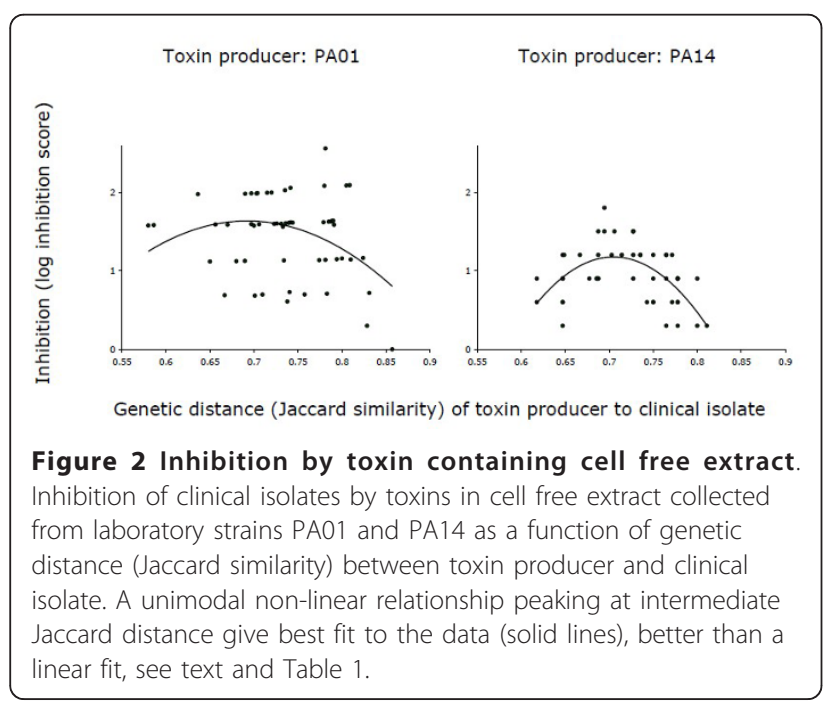

statistically significant 'hump' within the range of genetic distances examined. The evidence for an internal hump is somewhat weaker for PA01 than PA14 but we note that our test is conservative, as we have not included data on the effectiveness of either strain at inhibiting itself. As both of these values are zero (see Methods), including these values would produce a much more pronounced hump.

To verify that genetic distance correlates with resource use, we measured the metabolic similarity of toxin producing strains to the clinical isolates using Biolog plates (see Methods). Metabolic profiles become more divergent with increasing genetic distance, as expected, reflected in the significantly negative linear relationship observed between Jaccard distance and metabolic correlation between pairs of strains (PA01: slope \pm standard error $=$ $-0.493 \pm 0.213$; multiple $\mathrm{R}^{2}=0.098, t_{, 49}=-2.312, P=$ 0.025; PA14: slope \pm standard error $=-0.644 \pm 0.208$, multiple $\left.\mathrm{R}^{2}=0.164, t_{49}=-3.104, \mathrm{P}=0.0032\right)$. These results lend support to the idea that genetic distance is linked to ecological divergence. It is further notable that inhibition score peaked at intermediate metabolic similarities for both PA01 and PA14 but was statistically significant only for PA14 (see Additional file 1: Table S1 and Additional file 2: Figure S1; F-ratio test on the fitting of the quadratic term, PA01: $\mathrm{F}_{1,48}=0.176, P=0.68$; PA14: $\left.\mathrm{F}_{1,42}=7.00, P=0.011\right)$.

It is not immediately obvious why we detected a significant quadratic relationship between inhibition score and metabolic similarity in one strain but not the other. One possibility is that the Biolog plates we used here, which provide profiles on carbon substrate metabolism, represent one of many possible dimensions along which ecological divergence can proceed. Under this interpretation, metabolic divergence in carbon substrate use may reflect a correlated response to divergence in other ecologically important factors such as ability to grow as a biofilm, resistance to various stressors like $\mathrm{pH}$, temperature, or salinity, and possibly even predation, that we did not measure. Thus we would still expect to see some relationship between metabolic similarity and genetic distance, as we did for PA01, even if this is not the sole target of ecological divergence. There are any number of other differences between PA01 and PA14 that could be responsible for this difference. PA14 has a slightly larger genome than PA01 (6.5 Mbp and 6.3 Mbp, respectively) and contains a number of unique 'pathogenicity islands' that are thought to be associated with a generally increased level of virulence in most hosts [34]. It also is thought to produce only R- and F-type pyocins, whereas PA01 produces all three types (R, F, and S) [4]. It is notable that S-pyocins differ from both R-and F-pyocins in that they are oligopeptides whereas $\mathrm{R}$ - and F-pyocins are both phage-like structures. Why or how the differences 
Table 1 Linear and quadratic regressions of inhibition of clinical isolates by sterile (non heat treated) cell free extract of PA01 and PA14 cultures as function of genetic distance (Figure 2)

\begin{tabular}{|c|c|c|c|c|c|c|c|}
\hline Source & df & Value & St Error & $t$ & P-value & Multiple $\mathrm{R}^{2}$ & $\overline{A I C}$ \\
\hline PA01 Linear model & & & & & 0.072 & 0.059 & 90.91 \\
\hline Intercept & 1 & 3.27 & 0.969 & 3.38 & 0.0014 & & \\
\hline Linear term & 1 & -2.41 & 1.31 & -1.84 & 0.072 & & \\
\hline Residual SE & 53 & & 0.55 & & & & \\
\hline PA01 Quadratic model & & & & & 0.010 & 0.160 & 86.94 \\
\hline Intercept & 1 & -17.00 & 8.81 & -2.08 & 0.043 & & \\
\hline Linear term & 1 & 53.94 & 22.61 & 2.38 & 0.021 & & \\
\hline Quadratic term & 1 & -38.89 & 15.58 & -2.50 & 0.016 & & \\
\hline Residual SE & 52 & & 0.53 & & & & \\
\hline PA14 Linear model & & & & & 0.15 & 0.044 & 39.80 \\
\hline Intercept & 1 & 1.99 & 0.71 & 2.81 & 0.0072 & & \\
\hline Linear term & 1 & -1.45 & 0.98 & -1.48 & 0.15 & & \\
\hline Residual SE & 47 & & 0.36 & & & & \\
\hline PA14 Quadratic model & & & & & $<0.0001$ & 0.345 & 26.08 \\
\hline Intercept & 1 & -37.51 & 8.62 & -4.35 & 0.0001 & & \\
\hline Linear term & 1 & 109.8 & 24.23 & 4.53 & $<0.0001$ & & \\
\hline Quadratic term & 1 & -77.88 & 16.95 & -4.59 & $<0.0001$ & & \\
\hline Residual SE & 46 & & 0.30 & & & & \\
\hline
\end{tabular}

in genome content, size, or pyocin identity affects the relationship between inhibition score and metabolic similarity remains an open question, however.

What agents are responsible for killing in our experiments? Bacteriophage were clearly not responsible. If bacteriophage were causing the inhibition of clinical isolates, they would be able to amplify themselves in an exponential culture of the same clinical isolate. This was not the case (see Methods). Three lines of evidence suggest, rather, that toxic compounds such as pyocins or exotoxins excreted by PA01 and PA14 are the main killing agent. The first is that PA01 and PA14 are not killed by their own supernatant. Such a result is consistent with the idea that the toxins are pyocins, as pyocin production involves specific immunity genes that confer resistance by preventing lysis in non-producing kin $[4,5,35,36]$, although it does not rule out the possibility that other toxins with similar immunity properties are also involved. If killing were associated with a non-specific toxic compound such as some waste product, we would have expected both producer strains to be susceptible to killing and killing would most likely also not depend on genetic or metabolic similarity. Second, repeating the inhibition assay with heat-treated supernatant eliminates killing (Figure 3; both linear and quadratic regressions are non-significant), providing strong support for the idea that the killing compounds are proteins. Third, and most interestingly, inhibition by PA01 is stronger, on average, than that by PA14 (mean log inhibition score for PA01 $=1.51$; mean log inhibition score for PA14 = 0.95; t-test, $\left.t_{93}=6.05, P<0.0001\right)$, a result that is likely due to the fact that PA01 produces a larger array of pyocins than PA14, including S-type pyocins [4].

Although these three lines of evidence point suggestively to pyocins as being the main killing agent, we have not conducted an explicit test of this hypothesis by, for example, repeating our assays with pyocin knock-out strains. Although it may be possible to conduct such a test by focusing on the prtR/ $\mathrm{N}$ regulator, which is thought to be a global regulator of known pyocins [4,5], it is not clear that such a test would be conclusive since a number of the pyocins in both PA01 and PA14 have yet to be isolated $[18,19]$ and there may exist other exotoxins that behave in similar ways to pyocins. Note also that knowing the mechanism of killing, while of obvious interest, is in many ways of secondary importance to the observation that the

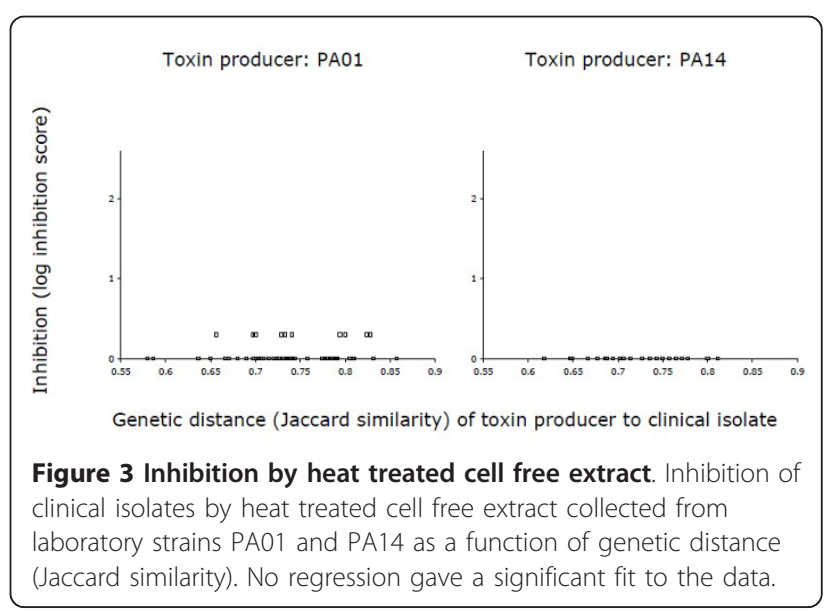


effectiveness of killing depends in a regular way on genetic distance, at least in the strains we have studied here.

Our main result is that the strength of antagonistic interactions peak at intermediate genetic distance. This pattern is strikingly similar to that expected from theoretical [37] and experimental $[38,39]$ kin selection models for selection using mixed populations of two strains at various ratios to adjust relatedness and considering one bacteriocin and one immunity protein. These models have emphasized how the cost of bacteriocin production is affected by the social environment: bacteriocin production is not favored when producers are both common, because the majority of competitors are kin and so immune to the bacteriocin, and rare, because there are now too few kin to enjoy the benefits of the extra resources. This is clearly not an appropriate interpretation of our results because we did not manipulate the frequency of producers and non-producers in our experimental system to adjust relatedness, as Inglis et al. [38] have done using degree of kinship as a measure of relatedness.

Rather, our results provide some evidence consistent with the idea that ecological divergence may be important in mediating social interactions. It is notable that the explanation for the ineffectiveness of toxins at inhibiting closely related genotypes (i.e. short genetic distance) in our experiment is likely similar to that in kin selection models: they share a degree of immunity to each other's toxins. However, the ineffectiveness of toxins against distantly related genotypes in our system is probably not directly tied to kin selection. Because increasing genetic divergence is accompanied by reduced overlap in resource use, distantly related genotypes are unlikely to compete for similar resources and so the resources liberated through antagonism are therefore unlikely to benefit the producer $[8,40]$. The production of antagonistic traits such as bacteriocins in this situation is therefore likely to be costly and so selection should lead to decreased levels of antagonism. Our observation of decreased antagonism among distantly related strains, at least for PA14, is consistent with this interpretation.

This interpretation is in accordance with the idea that the evolution of specific antagonism against conspecifics, as is often observed for bacteriocins, could evolve as a direct response to intraspecific resource competition and is consistent with models describing how fitness varies as a function of the strength of resource competition between types: the strength of resource competition, and so the loss of fitness, is highest when resource overlap is intermediate [41]. To the extent that the opportunity or intensity of resource competition is enhanced through the physical proximity of co-occurring strains in a given habitat [42], such as a CF lung, then this may further promote the evolution of antagonistic interactions such as those mediated by bacteriocins. It remains to be seen whether our results are specific to the strains we used in this study or whether they apply more broadly to non-CF strains of $P$. aeruginosa or other species. This will be an important avenue for future research.

It is not possible with our data to distinguish the specific mechanisms causing variation in toxin susceptibility. If bacteriocins are indeed responsible for killing, then one possibility is that selection targets the total amount of bacteriocin production or the efficiency with which bacteriocins inhibit or kill their victims. It is also possible that the target of selection is the number of receptor sites for bacteriocins in target strains. Deciding among these alternatives requires follow-up experiments that focus on finding the evolutionary origin of bacteriocins using direct competition experiments of producer stains and several target strains to ask under what conditions and by what mechanism bacteriocins aid producer populations to invade populations of sensitive strains [43]. These experiments would however be very elaborate since the effect of many complicating factors such as frequency dependence, cross-feeding, the viscosity of the environment and exact costs of producing bacteriocins would have to be determined for the interaction of the producer and each target strain. It is even possible that the high specificity of bacteriocins results from their having evolved initially as a byproduct of selection for fertility-recognition systems such as conjugation that were later co-opted for use as bacteriocidal agents [49]. Investigating the relationship between bacteriocin diversity and conjugation frequency or recombination could help shed some light on this issue.

Our results have important implications for understanding of the dynamics of infection in clinical settings. We have firmly established that toxic compounds with high specificity mediate bacterial interactions as antagonistic agents, for instance in structuring pathogen populations in patients with a mixed $P$. aeruginosa infection [12]. Social evolution theory predicts that selection for antagonism among pathogenic strains should be accompanied by reduced virulence to the host. The consequences of $P$. aeruginosa infection on patient morbidity and mortality may therefore depend to some extent on the particular strains present. Furthermore, it is notable that recent research on CF patients from Ontario suggests that $25 \%$ of Ontario patients who are infected with $P$. aeruginosa are infected with one of two predominant epidemic strains. It may be that the predominance of these epidemic strains is due to the production of specific antagonistic agents such as pyocins [13]. This is an intriguing hypothesis that awaits further testing. As a start, we have confirmed that three of our clinical isolates produce toxic substances that kill or inhibit other clinical isolates (data not shown). Thus the antagonistic interactions we have studied here do happen among clinical 
isolates and are not just the consequence of using strains PA01 and PA14 as producers in our study [13].

Understanding the way toxins such as pyocins kill $P$. aeruginosa strains, and how this is modulated by genetic relatedness, may also provide insight into the development of novel therapeutic interventions, for example by evolving pyocins specifically against strains that predominate in infections. They can thus be considered designer drugs $[7,23,44,45]$ and will be a much more direct agent to treatment of the disease than the current practice of using broad spectrum antibiotics against which wide spread resistance exists [46]. Interestingly, pyocins are not new in a clinical setting: it has been shown that pyocins slow down the development of several forms of cancer in mammalian cells [47]. Also, membrane vesicles produced by $P$. aeruginosa have been suggested as novel therapeutic agents [23]. However they may be even more effective when used in a targeted way against known infections. The similarity between strains can then be used as a predictor of the intensity of the antagonistic interaction and thus the effectiveness of the pyocin.

\section{Conclusions}

Using clinical and laboratory strains of Pseudomonas aeruginosa, we found that the level of antagonism between toxin producing and target strains is maximal at intermediate genetic and metabolic similarity between producer and target strain. We explained this result in the context of resource competition: resource competition is expected to be maximal for strains that are not your kin but also not completely unrelated since those strains do not share the same need for resources and are less likely to be a competitor. Our results suggest that the importance of antagonism and perhaps other social interactions between bacteria are modulated by the strength of resource competition.

\section{Methods}

\section{Bacterial strains and culture conditions}

We used standard laboratory strains Pseudomonas aeruginosa strains PA01 and PA14 and 55 natural P. aeruginosa isolates collected from cystic fibrosis patients. Infection with $P$. aeruginosa is associated with increased morbidity and mortality for CF patients, irrespective of lung function. Both population-based and case-control studies have demonstrated that infection with $P$. aeruginosa bacteria appears to be an independent prognostic factor that carries with it an increased risk of death $[38,40]$. Strains used here were isolated from sputum samples obtained from multiple patients all of whom had chronic endobronchial infections. Clinical P. aeruginosa isolates were collected between September 2005 and June 2008 from adult patients with confirmed cystic fibrosis who attended one of the seven Ontario adult cystic fibrosis clinics or who attended smaller outreach clinics [24]. These 7 clinics provide secondary and tertiary care to more than $97 \%$ of all CF patients in Ontario. Patients were included in the study if they were $\geq 18$ years of age, able to spontaneously produce sputum, and if they had a confirmed diagnosis of cystic fibrosis (a sweat chloride value higher than $60 \mathrm{mmol} /$ litre and/or 2 disease-causing mutations). The research ethics board (The Ottawa Hospital Research Ethics Board) of all the participating centers approved the study, and all participants provided written informed consent. Patients provided sputum samples which were couriered on ice to the central laboratory in Ottawa. To detect $P$. aeruginosa and other bacterial pathogens, sputum was plated onto the following selective and nonselective media: Columbia blood agar plate (PML), MacConkey agar plate (PML), and Pseudomonas aeruginosa selective agar plate (Oxoid). Plates were incubated at $35^{\circ} \mathrm{C}$ for 48 hours and $P$. aeruginosa colonies were identified by oxidase testing, TSI, arginine and growth at $42^{\circ} \mathrm{C}$. If $P$. aeruginosa was isolated, then two distinct $P$. aeruginosa colony morphotypes from each sputum were worked up for molecular typing, and five $P$. aeruginosa isolates derived from each sputum were frozen at $-70^{\circ} \mathrm{C}$.

To prepare for inhibition assays, strains were streaked from frozen on Pseudomonas Isolation Agar (Difco). Single colonies were used to inoculate liquid LB (bacto-tryptone $10 \mathrm{~g}$, yeast extract $5 \mathrm{~g}, \mathrm{NaCl} 10 \mathrm{~g}, \mathrm{dH}_{2} \mathrm{O} 1000 \mathrm{ml}$ ) and incubated under aerobic shaken conditions (150 rpm) at $37^{\circ} \mathrm{C}$ for 24 to $48 \mathrm{~h}$ to yield dense cultures.

\section{Estimation of genetic distance}

Genetic distance was estimated by comparing molecular genotypes of each $P$. aeruginosa isolate generated through pulsed-field gel electrophoresis (PFGE). PFGE is a wellaccepted method $[26,30]$ that differs from multi-locus sequence typing (MLST)-based approaches in that it includes the entire genome rather than just seven housekeeping genes. MLST profiling of our strains using seven housekeeping genes showed high similarity for those genes; what we would expect since they were all classified as $P$. aeruginosa. Studies [27] have shown that PFGE is more accurate when typing very closely related strains from the same species. To generate PFGE profiles, genomic DNA was prepared by a modification of a previously described method [48]. P. aeruginosa isolates were grown overnight at $37^{\circ} \mathrm{C}$ on Tryptone Soya Agar plates containing $5 \%$ sheep's blood. Colonies were suspended in buffer $(1 \mathrm{M} \mathrm{NaCl}, 10 \mathrm{mM}$ Tris- $\mathrm{HCl}[\mathrm{pH} 7.6])$ and $70 \mu \mathrm{L}$ of the suspension was mixed with an equal amount of $1.6 \%$ low melt agarose (Cambrex, East Rutherford, NJ). This mixture was pipetted into a plug mold (Bio-Rad, Hercules, CA) and allowed to solidify at room temperature. Plugs were added to plug lysis solution $(1 \mathrm{M} \mathrm{NaCl}, 100 \mathrm{mM}$ EDTA 
[pH 7.5], 0.5\% Brij-58, 0.5\% Sarcosyl, 0.2\% Deoxycholate, 6 $\mathrm{mM}$ Tris- $\mathrm{HCl}$ [pH 7.6], $1 \mathrm{mg} / \mathrm{mL}$ Lysozyme powder, 20 $\mu \mathrm{g} / \mathrm{ml}$ RNase) and incubated for $4 \mathrm{~h}$ at $37^{\circ} \mathrm{C}$ with shaking. Plugs were then placed in Proteinase $\mathrm{K}$ solution $(0.5 \mathrm{M}$ EDTA [pH 9-9.5], 1\% Sarcosyl, $50 \mu \mathrm{g} / \mathrm{ml}$ Proteinase K) and incubated overnight at $50^{\circ} \mathrm{C}$ with shaking. Plugs were washed 3-4 times with TE buffer (10 mM Tris- $\mathrm{HCl}[\mathrm{pH}$ 7.5], $0.1 \mathrm{mM}$ EDTA [pH 7.5]) at $37^{\circ} \mathrm{C}$ and then stored at $4^{\circ} \mathrm{C}$. DNA in a $2-3 \mathrm{~mm}$ piece of the gel plug was restricted using $20 \mathrm{U}$ SpeI (New England Biolabs, Ipswich, MA) in a reaction volume of $0.2 \mathrm{~mL}$ at $37^{\circ} \mathrm{C}$. The digestion products were melted and electrophoresis was performed on a $1.0 \%$ agarose gel, in 0.5X TBE (VWR International Ltd, Mississauga, ON), using a CHEF DR III apparatus (Bio-Rad, Hercules, CA). Electrophoresis conditions were as follows: $20 \mathrm{~h}$ at $6 \mathrm{~V} / \mathrm{cm}$ with switch times of $5 \mathrm{~s}$ to $45 \mathrm{~s}$ with a linear ramping factor. Using the ladder, all banding patterns were inspected for the presence/absence of a visible band at 51 locations. These presence/absence data were used to calculate the genetic distance by calculating the Jaccard similarity (Jaccard distance equals 1- Jaccard similarity) of natural isolates to both laboratory strains PA01 and PA14: $J^{\prime}=\frac{M_{11}}{M_{01}+M_{10}+M_{11}}$ where $M_{\mathrm{ij}}$ represents the total number of positions where bands are present $(i=j=1)$, or when one strain or the other possesses a band $(i \neq j)$. Other measures of similarity such as the Hamming distance, Dice coefficient and correlation coefficient gave similar qualitative results. We used R software (version 2.6.1) to calculate distance measures and for all statistical analyses.

\section{Estimation of metabolic similarity}

Resource use was measured using BIOLOG GN2 plates that consist of different wells with a total of 95 different carbon sources. All 55 clinical isolates and strains P. aeruginosa PA01 and PA14 were grown up in liquid LB medium. From a dense stationary phase culture, $20 \mu \mathrm{l}$ was added to $20 \mathrm{ml}$ of a minimal salts medium $\left(\mathrm{Na}_{2} \mathrm{HPO}_{4} 6.7\right.$ g, $\mathrm{KH}_{2} \mathrm{PO}_{4} 3 \mathrm{~g}, \mathrm{NaCl} 0.5$ g, NH $\mathrm{NH}_{4} \mathrm{Cl} .0$ g,

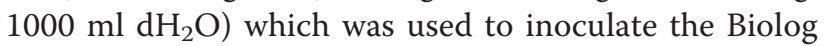
plates after a $2 \mathrm{~h}$ starvation period. For clinical isolates, 1 Biolog plate was used, for P. aeruginosa PA01 and PA14 three replicate plates were used. Right after inoculation and after $48 \mathrm{~h}$ of incubation at $37^{\circ} \mathrm{C}$, the $\mathrm{OD}(590 \mathrm{~nm})$ was measured of all wells. The difference in OD at the two time points is a measure of how well a given strain is able to use a given resource. To quantify the metabolic similarity, we calculated the correlation coefficient between the OD values of the different strains.

\section{Inhibition assays}

The strains $P$. aeruginosa PA01 and PA14 were assayed for their ability to produce toxic compounds that can inhibit the natural $P$. aeruginosa isolates collected from CF patients using a method adopted from Jacob 1954 [14]. Bacterial cells of dense LB cultures ( $48 \mathrm{~h}$ old) of PA01 and PA14 were spun down in a centrifuge. Supernatant was collected and filtered $(0.20 \mu \mathrm{m})$ and serially diluted in minimal salts medium [14]. For the assay asking if proteinaceous compounds are responsible for killing, the sterile supernatant was heated for $15 \mathrm{~s}$ at $100^{\circ} \mathrm{C}$. $0.5 \mathrm{ml}$ of a dense culture of a natural isolate was added to $3 \mathrm{ml}$ of molten semi solid LB (bacto-tryptone $10 \mathrm{~g}$,

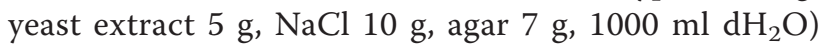
and poured out over the surface of a Petri dish containing minimal salts agar (as described above with $10 \mathrm{~g}$ of agar added) as an overlay. A dilution series of either non-heat treated or heat treated sterile supernatant was spotted on top of the layer of natural isolate, up to 11 spots of $15 \mu \mathrm{l}$ were spotted on a single Petri dish with overlay. Cultures were incubated for $48 \mathrm{~h}$ at $37^{\circ} \mathrm{C}$. The inverse of the highest dilution of sterile supernatant giving rise to inhibition was defined as the inhibition score, which is effectively a measure of the minimal inhibitory concentration (MIC). The inhibition scores were log transformed prior to analysis. No inhibition was observed when spotting sterile PA01or PA14 supernatant on top of an overlay with the same strain.

To exclude the possibility that bacteriophage are responsible for the observed inhibition, we performed a one-step growth assay as follows. The zones of inhibition formed on overlays of clinical isolates were transferred to an exponential liquid culture of growing cells of the same clinical isolate. After $24 \mathrm{~h}$, cell free extract was prepared and spotted onto a layer of the clinical isolate. A resulting clear zone of inhibition would be indicative of the presence of bacteriophage because a 24 h liquid culture of clinical isolate should contain even more bacteriophage than the initial culture since bacteriophage are able to reproduce with the appropriate host cells present. We found no evidence for the presence of bacteriophage.

\section{Additional material}

Additional file 1: Table S1. Inhibition of clinical isolates by toxins in cell
free extract collected from laboratory strains PA01 and PA14 as a
function of metabolic similarity (correlation coefficient) between toxin
producer and clinical isolate based on BIOLOG profiles. A unimodal non-
linear relationship peaking at intermediate metabolic similarity give best
fit to the data for producer PA14 (solid lines), better than a linear fit; for
PA01 no such relationship was found. See text and Supplemental Table.
Additional file 2: Figure S1. Inhibition of clinical isolates by toxins in
cell free extract collected from laboratory strains PA01 and PA14 as a
function of metabolic similarity (correlation coefficient) between toxin
producer and clinical isolate based on BIOLOG profiles. A unimodal non-
linear relationship peaking at intermediate metabolic similarity give best
fit to the data for producer PA14 (solid lines), better than a linear fit; for
PA01 no such relationship was found. See text and Supplemental Table. 


\section{Acknowledgements}

We thank anonymous reviewers and Andy Gardner for comments on this work and Tracy Giesbrecht, Talía Malagón and Danna Gifford for assistance. The Ontario Provincial Government, the Canadian Cystic Fibrosis Foundation and the National Research Council of Canada provided funding.

\section{Author details}

'Biology Department, University of Ottawa, 30 Marie Curie, Ottawa, ON K1N 6N5, Canada. ${ }^{2}$ Laboratory of Genetics, Wageningen University, Droevendaalsesteeg 1, 6708 PB Wageningen, the Netherlands. ${ }^{3}$ Ottawa Health Research Institute, 725 Parkdale Ave, Ottawa, ON K1Y 4E9, Canada.

\section{Authors' contributions}

Conceived the study: SES, SDA, RK; designed protocols: SES, JD, RD; performed experiments: SES, JD, RD; analyzed data: SES, JD, RK; collected clinical isolates and generated PFGE profiles: SDA; Wrote the paper: SES, RK. All authors commented on and approved the final manuscript.

Received: 22 June 2011 Accepted: 22 March 2012

Published: 22 March 2012

\section{References}

1. West SA, Diggle SP, Buckling A, Gardner A, Griffin AS: The social lives of microbes. Annu Rev Ecol Evol Syst 2007, 38:53-77.

2. Hamilton WD: The genetical evolution of social behaviour I and II. J Theor Biol 1964, 7:1-16.

3. Riley MA, Wertz JE: Bacteriocins: evolution, ecology and application. Ann Rev Microbiol 2002, 56:117-137.

4. Denayer S: Characterization of the receptors for the soluble pyocins S1, S2, and S3 of Pseudomonas aeruginosa. PhD Thesis Vrije Universiteit Brussel 191:2008.

5. Michel-Briand Y, Baysse C: The pyocins of Pseudomonas aeruginosa. Biochimie 2002, 84:499-510

6. Klaenhammer TR: Bacteriocins of lactic acid bacteria. Biochimie 1988, 70:337-349.

7. Gillor O, Nigro LM, Riley MA: Genetically engineered bacteriocins and their potential as the next generation of antimicrobials. Curr Pharm Des 2005, 11:1067-1075.0.

8. Kassen R, Bell G: The ecology and genetics of fitness in Chlamydomona $X$. The relationship between genetic correlation and genetic distance. Evolution 2000, 54:425-432

9. Cahill JF, Kembel SW, Lamb EG, Keddy PA: Does phylogentic relatedness influence the strength of competition among vascular plants? Perspect Plant Ecol Evol Systemat 2008, 10:41-50.

10. Smith DL, Smith EG, Pitt TL, Stableforth DE: Regional microbiology of the cystic fibrosis lung: a post-mortem study in adults. J Infect 1998, 1998(37):41-43.

11. Mowat E, Paterson S, Fothergill JL, Wright EA, Ledson MJ, et al: Pseudomonas aeruginos population diversity and turnover in Cystic Fibrosis chronic infections. Am J Respir Crit Care Med 2011, doi:10.1164/ rccm.201009-1430.

12. Harrison F: Microbial ecology of the cystic fibrosis lung. Microbiology 2007, 153:917-923.

13. Bakkal S, Robinson SM, Ordonez CL, Waltz DA, Riley MA: Role of bacteriocins in mediating interactions of bacterial isolates taken from cystic fibrosis patients. Microbiology 2010, 156:2058-2067.

14. Jacob F: Biosynthèse induite et mode d'action d'une pyocine, antibiotique de Pseudomonas pyocyane. Annales de l'Institut Pasteur 1954 86:149-160.

15. Kageyama M, Egami F: On the purification and some properties of a pyocin, a bacteriocin produced by Pseudomonas aeruginos. Life Sci 1962, 9:471-476.

16. Stover CK, Pham XQ, Erwin AL, Mizoguchi SD, Warrener P, et al: Complete genome sequence of Pseudomonas aeruginos, an opportunistic pathogen. Nature 2000, 406:959-964.

17. Parret AHA, De Mot R: Bacteria killing their own kind, novel bacteriocins of Pseudomona and other gamma-proteobacteria. Trends Microbiol 2002, 10:107-112.

18. Waite RD, Curtis MA: Pseudomonas aeruginos PAO1 pyocin production affects population dynamics within mixed-culture biofilms. J Bacteriol 2009, 191:1349-1354.
19. Köhler T, Donner V, van Delden C: Lipopolysaccharide as shield and receptor for R-pyocin-mediated killing in Pseudomonas aeruginos. Bacteriol 2010, 192:1921-1928.

20. De Jong A, Van Hijum SAFT, Bijlsma JJE, Kok J, Kuipers OP: BAGEL, a web-based bacteriocin genome mining tool. Nucleic Acids Res 2006, 34:W273-W279.

21. Bourke WJ, O'Connor CM, FitzGerald MX, McDonnell TJ: Pseudomonas aeruginos exotoxin A induces pulmonary endothelial cytotoxicity: protection by dibutyryl-cAMP. Eur Respir J 1994, 7:1754-1758.

22. Caldwell CC, Chen Y, Goetzmann HS, Hao Y, Borchers MT, et al: Pseudomonas aeruginosa exotoxin pyocyanin causes cystic fibrosis airway pathogenesis. Am J Pathol 2009, 175:2473-2488.

23. Kudurugamuwa JL, Beveridge TJ: Bacteriolytic effect of membranve vesicles from Pseudomonas aeruginos on other bacteria including pathogens: conceptually new antibiotics. J Bacteriol 1996, 178:2767-2774.

24. Aaron SD, Vandemheen KL, Ramotar K, Giesbrecht-Lewis T, Tullis E, et al: Infection with transmissible strains of Pseudomonas aeruginos and clinical outcomes in adults with cystic fibrosis. JAMA 2010, 304:2145-2153.

25. Corey M: Canadian Cystic Fibrosis Patient Registry Canadian Cystic Fibrosis Foundation; 1999.

26. Melles DC, Van Leeuwen WB, Snijders SV, Horst-Kreft D, Peeters JK, et al: Comparison of multi-locus sequence typing (MLST), pulsed-field gel electrophoresis (PFGE), and amplified fragment length polymorphism (AFLP) for genetic typing of Staphylococcus aureu. J Microbiol Methods 2007, 2007(69):371-375.

27. Speijer H, Savelkoul PHM, Bonten MJ, Stobberingh EE, Tjhie JTH: Application of different genotyping methods for Pseudomonas aeruginos in a setting of endemicity in an intensive care unit. J Clin Microbiol 1999, 37:3654-3661.

28. Anthony M, Rose B, Pegler MB, Elkins $M$, Service $H$, et al: Genetic analysis of Pseudomonas aeruginos isolates from the sputa of Australian adult cystic fibrosis patients. J Clin Microbiol 2002, 40:2772-2778.

29. Tenover FC, Goering RV: Methicillin-resistant Staphylococcus aureu strain USA300: origin and epidemiology. J Antimicrob Chemother 2009, 64:441-446.

30. Cooper JE, Feil EJ: Multilocus sequence typing - what is resolved? Trends Microbiol 2004, 12:373-377.

31. Seo Y, Galloway DR: Purification of the pyocin S2 complex from Pseudomonas aeruginos PA01: analysis of DNase activity. Biochem Biophys Res Commun 1990, 172:455-461.

32. Moreno MRF, Beart B, Denayer S, Cornelis $P$, De Vuyst L: Characterization of the amylovorin locus of Lactobacillus amylosvoru DCE471, producer of a bacteriocin active against Pseudomonas aeruginos, in combination with colistin and pyocins. FEMS Microbiol Lett 2008, 286:199-206.

33. Mittelbach GG, Steiner CF, Scheiner SM, Gross KL, Reynolds HL, et al: What is the observed relationship between species richness and productivity? Ecology 2001, 82:2381-2396.

34. Lee DG, Urbach JM, Wu G, Liberati NT, Feinbaum RL, et al: Genomic analysis reveals that Pseudomonas aeruginos virulence is combinatorial. Genome Biol 2006, 7:R90

35. Riley MA, Goldstone CM, Wertz JE, Gordon D: A phylogenetic approach to assessing the targets of microbial warfare. J Evol Biol 2003, 16:690-697.

36. Riley MA: Molecular mechanisms of bacteriocin evolution. Annu Rev Genet 1998, 32:255-278.

37. Gardner A, West SA, Buckling A: Bacteriocins, spite and virulence. Proc Roy Soc Lond B 2004, 271:1529-1535.

38. Inglis RF, Gardner A, Cornelis P, Buckling A: Spite and virulence in the bacterium Pseudomonas aeruginos. PNAS 2009, 106:5703-5707.

39. Inglis RF, Roberts PG, Gardner A, Buckling A: Spite and scale of competition in Pseudomonas aeruginos. Am Nat 2011, 178:276-285.

40. Bell G: Selection, the mechanism of evolution New York: Oxford University Press; 2008.

41. Doebeli M: An explicit genetic model for ecological character displacement. Ecology 1996, 77:510-520

42. Hawlena H, Bashey F, Lively CM: The evolution of spite: population sstructure and bacteriocin-meidated antagonism in two natural populations of Xenorhabdu bacteria. Evolution 2010, 64:3198-3204.

43. Chao L, Levin BR: Structured habitats and the evolution of anticompetitor toxins in bacteria. PNAS 1981, 78:6324-6328.

44. Williams SR, Gebhart D, Martin DW, Scholl D: Retargeting R-type pyocins to generate novel bactericidal protein complexes. Appl Environ Microbiol 2008, 74:3868-3876. 
45. Nakayama K, Takashima K, Ishihara H, Shinomiya T, Kageyama M, et al: The R-type pyocin of Pseudomonas aeruginos is related to $\mathrm{P} 2$ phage, and the F-type is related to lambda phage. Mol Microbiol 2000, 28:213-231.

46. Brown P, Butler S, Nelson J: Pseudomonas cepaci in adult cystic fibrosis: accelerated decline in lung function and increased mortality. Thorax 1993, 48:425-429.

47. Jones AM, Govan JRW, Doherty CJ, Dodd ME, Isalska BJ, Stanbridge TN, Webb AK: Spread of a multi-resistant strain of Pseudomonas aeruginos in an adult cystic fibrosis clinic. Lancet 2001, 358:557-558.

48. Laing FPY, Ramotar K, Read RR, Alfieri N, Kureishi A, Henderson EA, Louie TJ: Molecular epidemiology of Xanthomonas maltophili colonization and infection in the hospital environment. J Clin Microbiol 1995, 33:513-518.

49. Reeves P: The Bacteriocins. Bacteriological Reviews 1965, 29:24-45.

doi:10.1186/1471-2180-12-40

Cite this article as: Schoustra et al:: Antagonistic interactions peak at intermediate genetic distance in clinical and laboratory strains of Pseudomonas aeruginosa. BMC Microbiology 2012 12:40.

\section{Submit your next manuscript to BioMed Central and take full advantage of:}

- Convenient online submission

- Thorough peer review

- No space constraints or color figure charges

- Immediate publication on acceptance

- Inclusion in PubMed, CAS, Scopus and Google Scholar

- Research which is freely available for redistribution

Submit your manuscript at www.biomedcentral.com/submit 